\title{
Estudio comparativo doble ciego de los efectos terapéuticos de Neomicina, Lactobacilo y Placebo en infección enteral por Escherichia Coli Enteropatógeno
}

DRES. VAlERIA PRADO". IGUR MIMICA *.

Uno de los problemas que habitualniente sc le plantca al pediatra frente a un caso de diarrea es la decisión de usar o no un agente antibacteriano aparte de las medidas dietéticas y de hidratación para el tratamiento de este cuadro.

Se ha postulado que para algunos agentes infecciosos cnterales especialmente Salmonella, la administración de agentes antimicrobianos puede influenciar desfavorablemente la respuesta clínica y bactcriológica del paciente por lo cual nuestro criterio hasta ahora, cuando desconocemos la etiología específica, ha sido abstenemos de usar antibióticos, dada la relativa baja incidencia del Escherichia Coli Enteropatógeno (ECEP) encontrada hasta ahora en nuestra área (1).

De un estudio efectuado por nosotros anteriormente, conocíamos la real incidencia y la sensibilidad in vitro del ECEP frente a diferentes agentes antimicrobianos (2). Estimimos que para cviluar un agente terapéutico frente a una infección por ECEP no nos bastaría conocer sólo la acción in vitro de este agente frente a la especie en estudio, sino que deberíamos analizar la respuesta clínica y bacteriológica in vivo.

Por otra parte, distintas publicaciones han señalado la eficacia del uso de ciertas especies de lactobacilos en el tratamiento y prevención de distintos trastornos de origen enteral, probablemente por un mecanisno de competencia bjológica, entre estos lactobacilos y distintas especies de enterobacteriáccas, acción que ha sido además demostrada in vitro (3) (4) (5).

Dada la magnitud que ticne el problema de la infección por ECEP en nuestro medio hospitalario decidimos efectuar un estudio doble ciego con el fin de tratar de encontrar la medida terapéutica

\footnotetext{
* Departamento Mcclicina Experimental, Linidacl de Micrabiulagia. Area Uriente.
}

más efiçaz frente a la infección enteral causada por esta especic. Con los antecedentes que nos señalaba la literatura y nuestra propia experiencia in vitro decidimos tratar a los pacientes con infección por ECEP con tres medidas terapéuticas diferentes: Neomicina-Lactobacilo y Placebo, con el fìn de comparar lá respuesta clínica y bacteriológica de ellos.

Material y MÉTodos. Se estudió un número total de 51 enfermos, lactantes, con infección entcral por ECEP diagnosticadas por el test de Inmunofluorescencia directa.

Los pacientes por azar (sorteo) ingresaban a uno de estos 3 grupos:

- El primer grupo: 16 pacientes, recibió exclusivamente medidas dietéticas y de hidratación asociadas a un placcbo constituidos por 10 gramos de glucosa.

-. El scgundo grupo: 16 pacientes, recibió medidas ctietéticas e hidratación más Neomicina en dosis de $50 \mathrm{n} 1 \mathrm{gr} / \mathrm{Kg}-\mathrm{p} /$ día por un plazo de 7 días.

- El tercer grupo: 19 pacientes, recibió aparte de las medidas de hidratación y dietéticas, lactobacilos en dosis aproxinadas de $2 \times 10^{9} \mathrm{bac}-$ terios por niño y por día durante 7 días.

Tanto los médicos tratantes como los autores de este trabajo no conocían en el momento de evaluar la respuesta clínica y bacteriológica a cuál de los tres grupos pertenecía el paciente en estudio.

Para cvaluar la respuesta clínica se consideraron: duración de la diarrea, duración de la deshidratación, número de días de hospitalizacjón.

Para cvaluar lá respuesta bacteriológica se determinó la desaparición o persistencia del ECEP 
en la deposición efectuando un control de Inmunofluoreseencia directa en deposiciones a los 6 días de iniciado tratamiento.

\section{RESULTADOS Y COMENTARIOS.}

T A B L A No 1

ESTUDHO TERAPEUTICO DOBLE CIEGO. DISTRIBUCION SEGUN EDAD DE 51 LACTANTES CON INFECCION ENTERAL POR ECEP.

\begin{tabular}{c|c|c|c}
\hline Edad & $\begin{array}{c}\text { Crupo } \\
\text { Neomicina }\end{array}$ & $\begin{array}{c}\text { Grupo } \\
\text { Placebo }\end{array}$ & $\begin{array}{c}\text { Grupo } \\
\text { Lactobacilo }\end{array}$ \\
\hline$<6$ moses & 14 & 12 & 13 \\
$>6$ meses & 2 & 4 & 6 \\
\hline To t a 1 & 16 & 16 & 19 \\
\hline
\end{tabular}

$\mathrm{X}^{2}=1.62 \mathrm{~N}$. S. (No significativo).

La tabla Nọ 1 muestra la distribución según edad en los distintos grupos experimentales y el estudio estadístico señala que no hay diferencias significativas en esta distribución.

\section{TA B L A No 2}

ESTUDIO TERAPEUTICO DOBLE CIEGO. DISTRIBUCION SEGUN ESTADO NUTRITIVO DE SI LAC. IANTES CON INFECCION ENTERAL POR ECEP

\begin{tabular}{l|c|c|c}
\hline Estato mutritivo & $\begin{array}{c}\text { Grupo } \\
\text { Neomicina }\end{array}$ & $\begin{array}{c}\text { Grupo } \\
\text { Placebo }\end{array}$ & $\begin{array}{c}\text { Grupo } \\
\text { Lacto- } \\
\text { bacilo }\end{array}$ \\
\hline Eutrofia & 2 & 3 & 3 \\
Desnutrición I grado & 2 & 2 & 1 \\
Desnutrición II grado & 9 & 9 & 7 \\
Desnutrición III grado & 3 & 2 & 8 \\
\hline T o t a 1 & 16 & 16 & 19 \\
\hline
\end{tabular}

$X^{2}=3,77$ N. S. (No significativo).

La tabla No 2 muestra la distribución según el estado nutritivo de los 3 grupos estudiados y el cálculo estadístico señala que no hay diferencias significativas en esta distribución.
TABLA No 3

ESTUDIO TERAPEUTICO DOBLE CIEGO. DURACION DE LA DIARREA EN LACTANTES CON INFECCION ENTERAL POR ECEP

\begin{tabular}{l|c|c|c}
\hline & $\begin{array}{c}\text { Grupo } \\
\text { Neomi- } \\
\text { cina }\end{array}$ & $\begin{array}{c}\text { Grupo } \\
\text { Placebo }\end{array}$ & $\begin{array}{c}\text { Grupo } \\
\text { Lacio- } \\
\text { bacilo }\end{array}$ \\
\hline Promedio & 4,00 & 7,07 & 8,22 \\
Desviación standard & 2,00 & 2,74 & 4,97 \\
No de pacientes & 16 & 15 & 18 \\
\hline
\end{tabular}

$\mathrm{tN}-\mathrm{P}=3,78 * 3$.

tL $-\mathrm{P}=0.29 \mathrm{~N}$. S.

** Altamente significativo.

N. S. No significativo.

La tabla No 3 muestra el promedio de días de duración de la diarrea en los grupos estudiados. Según los cálculos estadísticos, hay diferencias significativas en la duración de la diarrea entre el grupo placebo y el grupo tratado con Neomicina y en cambio el tratamiento con lactobacilo no da una duración de la diarrea diferente del placebo.

T ABLA Nơ 4

ESTUDIO TERAPEUTICO DOBLE CIEGO. DURACION DE LA DESHIDRATACION EN LACTANTES CON INFECCION ENTERAL POR ECEP.

\begin{tabular}{|c|c|c|c|}
\hline & $\begin{array}{l}\text { Grupo } \\
\text { Neomi- } \\
\text { cina }\end{array}$ & $\begin{array}{l}\text { Grupo } \\
\text { Placebo }\end{array}$ & $\begin{array}{l}\text { Grupo } \\
\text { Lacto- } \\
\text { bacilo }\end{array}$ \\
\hline $\begin{array}{l}\text { Promedio días } \\
\text { con fleboclisis }\end{array}$ & 1,63 & 4,20 & 3,83 \\
\hline Desviación standard & 1,09 & 2,48 & 4,41 \\
\hline No de pacíentes & 16 & 15 & 18 \\
\hline
\end{tabular}

La tabla $N^{\circ} 4$ muestra la duración del estado de deshidratación de los grupos estudiados expresado de días con fleboclisis.

Los cálculos estadísticos muestran que bay diferencias altamente significativas entre la duración de la deshidratación del grupo tratado con Ncomicina y el grupo Placebo. No se observan diferencias entre el grupo tratado con lactobacilo $\mathrm{y}$ el placebo. 
TAB L A NO 5

ESTUDHO TERAPEUTICO DOBLE CIEGO: DURACION DE LA HOSPITALIZACION EN LACTANTES CON INFECCION ENTERAL POR ECEP:

\begin{tabular}{|c|c|c|c|}
\hline & $\begin{array}{c}\text { Grupo } \\
\text { Neomi- } \\
\text { cina }\end{array}$ & $\begin{array}{l}\text { Grupo } \\
\text { Placebo }\end{array}$ & $\begin{array}{l}\text { Grupo } \\
\text { Lacto- } \\
\text { bacilo }\end{array}$ \\
\hline Promedio (días) & 14.78 & 17,93 & 19,89 \\
\hline Desviación standard & 4,66 & $9,35:$ & $9: 19$ \\
\hline No de pacientes & 14 & 15 & 18 \\
\hline
\end{tabular}

$\mathrm{IV}-\mathrm{P}=0,41 \mathrm{~N}$. $\mathrm{S}$.

$\mathrm{tL}-\mathrm{P}=0,60 \mathrm{~N} . \mathrm{S}$.

N. S. No significativo.

La tablit No 5 muestra el promedio de días de hospitalización en los 3 grupos de lactantes estudiados. Estadísticamente no se obsetvan diferencias en los pronedios. La duración de la hospitatización tho seria un buen índice comparativo ya que puede estirr influenciado por factores ajcnos a la experiencia como la aparición de otros cuadros patológicos agregados.

\section{TABLA $\mathrm{N}^{o} 6$}

ESTUDIO TERAPEUTICO DOBLE CIEGO. PERSISTENCIA DE LA DIARREA DESPUES DE INICIADO TRATAMIENTO EN LACTANTES CON INFECCION ENTERAL POR ECEP.

\begin{tabular}{l|c|c|c}
\hline & $\begin{array}{c}\text { Grupo } \\
\text { Neomicina }\end{array}$ & $\begin{array}{c}\text { Grupo } \\
\text { Placebo }\end{array}$ & $\begin{array}{c}\text { Grupo } \\
\text { Lacto- } \\
\text { bacilo }\end{array}$ \\
\hline Más de 5 dỉas & 3 & 11 & 12 \\
5 días o menos & 13 & 4 & 6 \\
\hline Tota 1 & 16 & 15 & 18 \\
\hline
\end{tabular}

$\mathrm{X}^{2}$ N-P-L $=11,37 * *$.

$X^{2}$ N-P $=7,24 * *$.

** Altamente significativo.

La tabla No 6 muestra la persistencia de la diarrea después de iniciado al tratamiento en los 3 grupos de estudio.

Las diferencias observadas en la duración de la diarrea es altamente significativa desde el punto de vista estadístico entre los 3 grupos y esta dife- rencia está dada primariamente por la diferencia de duración de la diarrea entre el grupo tratado con Neomicina y el grupo Placebo que da un $X^{3}=7,24$

TABLA NQ 7

ESIUDHO TERAIEUTICO DOBLE CIEGO. RESULTADO DEL CONTROL BACTERIOLOGICO A LOS 6 DIAS DE TRATAMIENTO EN LACTANTES CON INFECCYON ENTEKAL POR ECEP.

\begin{tabular}{|c|c|c|c|}
\hline Comtrol bacteriolongtint & $\begin{array}{c}\text { Grape } \\
\text { Neomi- } \\
\text { Cina }\end{array}$ & $\begin{array}{l}\text { Grupo } \\
\text { Placebo }\end{array}$ & $\begin{array}{l}\text { Grupo } \\
\text { Lacto- } \\
\text { bacilo }\end{array}$ \\
\hline I. F. positiva & 1 & 4 & 5. \\
\hline $\begin{array}{c}\text { L.F. negativa } \\
:\end{array}$ & 1.1 & 7 & 11 \\
\hline Tot a I & 12 & $11 \cdots$ & 16 \\
\hline
\end{tabular}

$\mathrm{X}^{*}=2,63 \mathrm{~N} . \mathrm{S}$.

N. S. = No significativo.

En la tabla $\mathrm{No} 7 \mathrm{fe}$ expresan los resultados de los controles bacteriológicos en base a test de Inmunofluorescencia directa efectuado a los 6 días de iniciado el tratamiento respectivo en cuda grupo. I. F. positiva significa persistencia det ECEP en el intestino.

Aunque estadísticamente en la evolución bacteriológica no observamos diferencias significativas, esto podría deberse a razones experimentales ya que en algunos casos no fue posible efectuar dicho control $y$ juntamente en los grupos que podrían haber dado unas diferencias: Neomicina y Placebo, hubo 4 casos en cada uno en que no se pudo efectuar el test de Inmunofluorescencia de control.

Estos resultados nos hacen plantear que la diarrea por ECEP debe ser tratada con un agente antimicrobiano ya que no batstan las medidas dietéticas exclusivas o cl uso de factores biológicos como es el lactobacilo y que en nuestro material la Neomicina ha demostrado ser útil.

Qucremos plantear el hecho que si en estudios posteriores efectuados en el Hospital de nuestra área, se demuestra en cada temporada de diarrea estival la persistencia de esta alta incidencia de infección por cali patógeno, está justificado a nuestro juicio, cuando las condiciones no permitan hacer un estudio etiológico precoz de la diarrea, el uso desde el primer día de hospitalización đel niño de un antibacteriano activo frente a ECEP. 
Concluslón, La ventaja de usar un agente antimicrobiano en el tratamiento de la infección enteral por coli patógeno en lactantes ha quedado plenamente demostrada. La Neomicina demostró satisfactorios resultados en la respuesta clínica. La administración de lactobacilos no demostró diferencias en la evolución clínica de la diarrea por ECEP con respecto al placebo.

\section{RESUMEN}

Se estudian 51 lactantes con infección enteral por ECEP. Por método doble ciego se sometian a tres esquemas terapéuticos; un grupo de 16 lac. tantes recibió placebo consistente en glucosa; a otro grupo de 16 lactantes se le administró Neomicina y un tercer grupo de 19 lactantes fue tratado con lactobacilos. Al cabo de 7 dias de tratamiento se efectuaron evaluaciones clinicas y bacteriológicas. El análisis estadístico de los resultados demostró claras venzajas del uso de Neomicina en infección enteral por ECEP.

\section{SUMMARY}

51 infants with diarrheal disease caused by pathogenic E. coli were studied with a double blind method.

A group of 16 infants received dextrose as a place- bo; a second group of 16 received Neomycin and third group of patients was treated with lactobacillus: clinical and bacteriological controls were performed at the seventh day of treatment. The statistical analysis concluded a clear advantage in the use of Neomycin in entheric infections by $E$, coli.

\section{Bibliograffa}

1.- Rossenstein, B. Salmonellosis in infants and childrens. J. of Ped. 70-1-1957.

2.-Prado, Valeria; Mimica, Igor; Donoso, Edo. Etiología bacteriana de la diarrea aguda del lactante, aportes de la Inmunofluorescencia. Estudio de Sensibilidad in vitro de los bacterios estudiados. (Congreso Nacional de Pediatría 1973).

3.- Alexander 1. G. Thrush bowel infection existence incidence, prevention and treatment, particularly by a lactobacillus acidophillus preparation. Curr. Med. Drugs 8: 3-11 Dic. 1967.

4.- Tramer Inhibitory effect of Lactobacillus. Nature 2: 11-204-5 July 9, 1966.

5.-Pene P. et. al. The colibacillus combination in the treatment of diarrhea in adults childrens and infants, Sem 40 p. Paris 42-241 420 Jan. 1966. 